\title{
Factors associated with health-related quality of life in adults with asthma. A cross-sectional study
}

\author{
Francisco-Javier Gonzalez-Barcala ${ }^{1 *}$, Ramon de la Fuente-Cid ${ }^{2}$, Mónica Tafalla $^{3}$, Javier Nuevo ${ }^{3}$ \\ and Francisco Caamaño-Isorna ${ }^{4}$
}

\begin{abstract}
Background: The measurement of health-related quality of life (HRQoL) is increasingly recognized as an important endpoint, as a reflection of the effects of the disease from a patient perspective. Our aim was to evaluate the factors determining the HRQoL in patients with asthma, according to the EQ-5D questionnaire.

Methods: Patients were included using multi-stage sampling, from Primary Care clinics from all the Autonomous Communities in Spain. The patients included were: over 18 years-old, with a confirmed diagnosis of asthma for at least one year, and had visited a Health Centre in the previous 2 years. The characteristics of the asthma disease, the adherence to treatment, the socio-demographic variables, the smoking habits, and the asthma control were collected using a questionnaire. The influence of the different variables included in the study on the EQ-5D was evaluated using multivariate logistic regression analysis.
\end{abstract}

Results: A total of 2,125 patients were finally included (57.7\% females, mean age 48 years). The response rate was 95.4\%. Some factors showed a considerable detrimental effect on the HRQoL of asthmatics. Advanced age, lower educational level and poor control of asthma are significantly associated with a worse quality of life in all the dimensions assessed by the EQ-5D scale. The baseline severity of the asthma, and having been admitted to hospital are related to a worse quality of life in 5 of the 6 dimensions analyzed.

Conclusion: In our study, we could identify some factors related to quality of life in asthma patients. The most important were advanced age, lower education level, and poor control of the asthma.

Keywords: Asthma, Quality of life, Risk factors, Adults

\section{Background}

The measurement of health-related quality of life (HRQoL) is increasingly recognized as an important endpoint, a reflection of the effects of the disease from a patient's perspective. It covers a multidimensional concept, not only associated with the disease itself and the medical actions developed for its management, but also with the physical, social and psychological functioning of the patient [1-5]. Although clinical and physiological parameters are needed to evaluate the disease, these are not sufficient to understand and assess how the patients perceive their state of health $[6,7]$.

\footnotetext{
* Correspondence: francisco.javier.gonzalez.barcala@sergas.es

${ }^{1}$ Pneumology Department, Clinic University Hospital, C/Choupana SN 15706, Santiago de Compostela, Spain

Full list of author information is available at the end of the article
}

It is known that asthma negatively influences the quality of life of the patients who suffer from it, but the determining factors are not fully understood. In fact, the most severe forms of the disease are associated with a worse quality of life, but this relationship is not linear $[8,9]$. The factors related to this aspect of the disease need to be identified in order to improve the quality of life of the patients [7-9]. Several questionnaires have been developed to assess HRQoL. Some are used for specific diseases, while others are generic [7].

The EuroQol-5D (EQ-5D) questionnaire is a generic tool for measuring HRQoL, applicable in healthy individuals as well as in patients with a specific disease, which seems to have demonstrated validity and reliability in asthma [7]. In this, five health dimensions, stratified into 3 levels, as well as visual analogue scale (VAS) are descriptively evaluated [7].

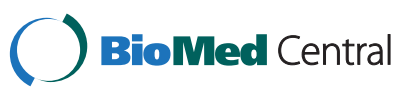


The EQ-5D is a generic HRQoL questionnaire, and although not specific for asthma, it is considered valid for cross-sectional population studies of patients with this disease [2].

Our aim was to evaluate the factors associated with HRQoL in patients with asthma, from a multidimensional perspective.

\section{Methods}

Patients were included, using multi-stage sampling, from Primary Care clinics from all the Autonomous Communities in Spain. The first sampling unit was the Family Doctors, with 182 doctors being selected. They, in turn, included between 12 and 20 consecutive patients who were seen at their clinics, and who met with the previously defined criteria [10]. The patients were contacted by telephone from the clinic by their own doctor, and the data was collected by personal interview between November 2007 and March 2008.

The patients included were those who were over 18 years-old (adult legal age in Spain), with a confirmed diagnosis of asthma for at least one year according to GINA criteria [11], who had visited a Health Centre in the previous 2 years, and signed the informed consent. Those individuals who, in the investigator's opinion, were unable to read or understand the questionnaires, or had Chronic Obstructive Pulmonary Disease, were excluded [10].

Data were collected by personal interview, carried out by the Family Doctors themselves, with no specific training for this study.

The HRQoL was assessed using the EQ-5D questionnaire, where the patients themselves evaluated their state of health in severity levels by dimensions (including the 5 dimensions: mobility, personal care, daily activities, pain/discomfort, anxiety/depression) which were assessed at three levels (no problems, moderate problems, serious problems). An assessment was also made on a more general VAS scale ranging from 0 (worst state of health) to 100 (better state of health) [12].

Control of the asthma was determined using the Asthma Control Questionnaire (ACQ) [13]. Those patients who obtained an ACQ score lower than 0.75 were considered as well controlled, and those with a score $\geq 0.75$ as not well controlled $[10,13]$.

Using a questionnaire specifically designed for the study, the characteristics of the asthma disease were collected, as well as the adherence to treatment, and the socio-demographic variables, including: age, gender, place of residence (rural/urban), and educational levels (primary school, secondary school, university).

As regards smoking, they were classified into never smokers (means never having smoked habitually, no more than an occasional cigarette), ex-smokers (have been active smokers, but have not smoked for at least 6 months), or active smokers (smoke habitually every day).

Obesity was classified based on the body mass index (BMI), establishing 3 groups, normal weight (less than $25 \mathrm{~kg} / \mathrm{m} 2$ ), overweight (between 25 and $30 \mathrm{~kg} / \mathrm{m} 2$ ) and obese (more than $30 \mathrm{~kg} / \mathrm{m} 2$ ).

The incidence of stressful events in the 15 days prior to completing the questionnaire was evaluated based on self-reporting by the patients, by asking them if they had suffered a stressful event in the previous 15 days, in general, without suggesting specific examples of a stressful events, with two response options, yes or no.

Treatment adherence was determined based on 3 variables: 1) level of therapeutic adherence according to the doctor; 2) frequency of forgetting the medication according to the patient; 3) importance of adherence according to the patient [10]. This last variable was determined by asking the patients about their level of agreement (from $0=$ disagree completely, to $10=$ agree completely) with the following sentence "Strict adherence to the medication prescribed by my doctor should improve my asthma symptoms"; and was stratified, by research team consensus, into two categories: $<8$ and $\geq 8$ [10].

The severity of the asthma (intermittent, mild persistent, moderate persistent, severe persistent) was determined in accordance with the criteria in the Global Initiative for Asthma guide (GINA) 2006, based on the condition of the patient before treatment was started [11].

The presence of allergy sensitization was reported by the patients themselves. Questions on going to an Emergency unit, to their Family Doctor or any hospital admissions during the year prior to the study were included in the questionnaire.

The basic treatment was classified into four, mutually exclusive, categories: 1) patients treated with oral corticosteroids in the previous year; 2) those treated with any combination of long-acting beta- 2 agonists and inhaled corticosteroids, with any other drug but without oral corticosteroids; 3 ) treated with inhaled corticosteroids without continually taking long-acting beta- 2 agonists, although they may take beta- 2 agonists on demand; 4) only beta- 2 agonists [10].

\section{Statistical analysis}

The mean, median, standard deviation, maximum and minimum values were calculated for the continuous variables, and the absolute and relative frequencies for the categorical variables.

The influence of the different variables included in the study on the 5 dimensions of the EQ-5D recoded dichotomically (without problems versus with problems) and the probability of obtaining values greater than the mean 
on the VAS scale were evaluated using multivariate logistic regression analysis. For the logistic regression model, all variables with a significance value of $\mathrm{P}<0.2$ in the univariate analysis were used as predictive variables in the multivariate analysis. The level of significance in the multivariate analysis was defined based on the confidence interval with an alpha error less than 0.05. The software SAS v8.2 was used. The study was approved by the Hospital Clínico San Carlos de Madrid Clinical Research Ethics Committee.

\section{Results}

A total of 2,125 patients were finally included, with $57.7 \%$ females, and a mean age of 48 years. The response rate was $95.4 \%$. The main characteristics of the patients included are summarized in Table 1.

Through the analysis of the different dimensions evaluated with the EQ-5D questionnaire, the worst results corresponded to anxiety/depression, where 32\% of asthmatics were shown to have problems. On the other hand, asthma seemed to have little effect on personal care, as only $8 \%$ mentioned problems on this aspect (Table 2).

Advanced age, a lower education level, greater baseline severity of the asthma, poor control of the asthma, and the need to be admitted to hospital had a detrimental effect on at least 4 of the 5 EQ-5D dimensions (Table 2). Analyzing the quality of life according to the VAS and with the EQ-5D index, the characteristics with the most significant influence on analyzing the QoL by dimensions maintained their impact. Other factors also demonstrated an independent effect, amongst which the most significant one corresponded to patients who had some recent stressful events, or who gave little importance to adherence to treatment (Table 3).

\section{Discussion}

It appears to be a current need to assess HRQoL in asthma, although it is still not clear which is the most suitable tool for assessing it [14]. EQ-5D is a generic HRQoL questionnaire that correlates well with asthma specific questionnaires. Also, the broader approach of generic questionnaires can give them a higher potential to pick up unexpected aspects or collateral effects of the disease. These two factors make it reasonably valid for population studies with asthmatic patients [5,15-17]. Furthermore, being a generic questionnaire, it helps in making the cost comparison with other chronic illnesses [14]. The response rate obtained in our study was relatively high (95.4\%), and probably associated, at least partly, with the simplicity and rapidity in completing the EQ-5D questionnaire; which also makes it easier to use in daily practice [18].
Our results appear to confirm the negative effect of asthma on HRQoL when assessed with the EQ-5D questionnaire, and this effect appears worse than that reported in the general Spanish population [19]. Only the pain/discomfort dimension and the values obtained on the VAS for the general population are similar to those of our asthmatic population, but there are significant differences in the rest of the dimensions [19].

Increasing age, lower educational level, poorer asthma control and requiring hospital admissions were significant determining factors of a poorer HRQoL in asthmatic patients in all the dimensions analyzed, as well as in the general HRQoL analyzed using the VAS.

Although in some studies with few patients [20], or with a relatively young population [21] no association was seen between age and HRQoL, the majority of authors mention a deterioration in HRQoL with increasing age $[5,8,22]$. Some factors associated with ageing could explain this result. On the one hand, there are changes in lung function, such as an increase in airway hyper-responsiveness, accelerated decline in forced expiratory volume in one second, higher prevalence of irreversible airway obstruction, increased air trapping, reduction in chest wall compliance, a decrease in static elastic recoil pressure of the lung, reduction in respiratory muscle strength, as well as changes in chest configuration which make respiratory movements difficult $[23,24]$. There are also changes in the immune system, immunosenescence, which increases susceptibility to infections and malignancy rates [25]. Likewise, a deterioration in sight and hearing, in motor abilities, or even incipient cognitive impairment, can make adherence to treatment difficult [23]. Finally, comorbidity is more frequent in advanced age, as such that it may increase the symptomatology, and even make it difficult to indicate some treatments that may be suitable for asthma, but contraindicated by some of the respiratory comorbidities [23,24].

Lower health literacy has been reported in patients with a lower education level, as well as, lower mathematical skills, more delayed diagnosis of asthma, poorer access to health care or less adherence to healthy lifestyles, which could contribute to the worsening of HRQoL observed in these patients [26-29].

Hospital admissions are a major predictor of a worse HRQoL in asthma [8]; but a worse HRQoL is also associated with a higher probability of hospital admissions [30].

Good control of the disease has a significant effect on a better HRQoL, which is in agreement with other authors [5,31]. However, to achieve good control of the disease does not imply obtaining an optimum HRQoL, as other factors, such as the presence of the disease itself, or the need for treatment and medical care, 
Table 1 Factors associated with health-related quality of life $(n=2,125)$

Gender
Female
Male
Age
$\geq 60$ years
40 to 59 years
18 to 39 years
BMI (Kg/ $\mathbf{m}^{\mathbf{2}}$ )
$\geq 30$
$\geq 25$ to 30
$<25$

\section{Educational level}

None

Primary

Secondary

University

\section{Occupation}

Non active worker

Active worker

Living status

Lives alone

Lives with someone

Place of residence

Rural

Urban

Family history of asthma

Yes

No

\section{Asthma severity}

Severe persistent

Moderate persistent

Mild persistent

Intermittent

\section{Smoking habit}

Never

Current or former

\section{Alcohol intake}

$\leq 22.5$ grams

$>22.5$ grams

\section{Pets at home}

Yes

No
$\%$ patients without problems

$883 / 1,227(72.0 \%)$

$726 / 898(80.8 \%)$

335/638 (52.5\%)

$551 / 704$ (78.3\%)

723/783 (92.3\%)

243/424 (57.3\%)

$656 / 873(75.1 \%)$

$709 / 826(85.8 \%)$

74/170 (43.5\%)

613/900 (68.1\%)

600/706 (85.0\%)

$319 / 345(92.5 \%)$

648/1,029 (63.0\%)

960/1,094 (87.7\%)

145/237 (61.2\%)

$1461 / 1,885$ (77.5\%)

632/859 (73.6\%)

977/1,265 (77.2\%)

$744 / 984(75.6 \%)$

865/1,141 (75.8\%)

28/90 (31.1\%)

449/706 (63.6\%)

655/774 (84.6\%)

476/554 (85.9\%)

1006/1,339 (75.1\%)

601/784 (76.7\%)

705/940 (75.0\%)

$732 / 944(77.5 \%)$

$473 / 626(75.6 \%)$
$1,134 / 1,497(75.7 \%)$
Table 1 Factors associated with health-related quality of life $(\mathbf{n}=\mathbf{2}, \mathbf{1 2 5})$ (Continued)

\begin{tabular}{lr}
\hline Allergy sensitization & \\
No & $871 / 1,201(72.5 \%)$ \\
Yes & $738 / 924(79.9 \%)$ \\
Stressful event last 15 days & \\
Yes & $207 / 307(67.4 \%)$ \\
No & $1,394 / 1,810(77.0 \%)$
\end{tabular}

Adherence to treatment (physician's point of view):

$31 / 40(77.5 \%)$

Poor

224/313 (71.6\%)

Acceptable

624/805 (77.5\%)

Good

562/743 (75.6\%)

Very good

168/224 (75.0\%)

How often do you forget your medication?

$>10$ times every month

$51 / 76(67.1 \%)$

6-10 times every month

$163 / 223(73.1 \%)$

1-5 times every month

$764 / 999(76.5 \%)$

Never

$631 / 827(76.3)$

Adherence is important (score, patient's point of view):

$<8$

$388 / 531(73.1 \%)$

$\geq 8$

$1,220 / 1,591(76.7 \%)$

Asthma treatment

Oral corticosteroids

$62 / 158(39.2 \%)$

$L A B A+I C$

Inhaled corticosteroids

$1,114 / 1,476(75.5 \%)$

180/209 (86.1\%)

$230 / 255(90.2 \%)$

SABA or LABA

$437 / 792(55.2 \%)$

$>1.50$

$0.75-1.50$

$<0.75$

$464 / 561(82.7 \%)$

708/772 (91.7\%)

Asthma control(physician's point of view):

Very poor

43/83 (51.8\%)

Poor

$172 / 322(53.4 \%)$

Controlled

$504 / 721(69.9 \%)$

Total control

$889 / 997(89.2 \%)$

Asthma control (patient's point of view)

Very poor

$11 / 41(26.8 \%)$

Poor

97/191 (50.8\%)

Controlled

432/666 (64.9\%)

Total control

$1,060 / 1,217(87.1 \%)$

Hospital admissions

Yes

54/179 (30.2\%)

No

$1,555 / 1,946(79.9 \%)$ 
Table 1 Factors associated with health-related quality of life $(\mathbf{n}=\mathbf{2 , 1 2 5})$ (Continued)

Number of hospital admissions

$\geq 2$

$10 / 52(19.2 \%)$

1

$44 / 127(34.6 \%)$

0

Emergency visits

Yes

$1,555 / 1,946(79.9 \%)$

$503 / 810(62.1 \%)$

No

Number of emergency visits

$\geq 3$

$1-2$

0

Family physician visits

No

Yes

Number of family physician visits

0

$<4$

$\geq 4$

$675 / 786(85.9 \%)$

$831 / 1,221(68.1 \%)$

although improving control of the asthma, have an effect on the HRQoL [31].

Although there is a known relationship between asthma and psychological factors, the impact of psychological distress on the health of asthmatics and its determining factors are not well described [32]. Some authors observed a worse quality of life in asthmatics with anxiety and/or depression [33-35]. On the other hand, Heaney et al., observed that the improvement in asthma control led to a better quality of life, but did not change the psychiatric symptoms. [36]. Furthermore, there is no single method to assess negative life events (NLE), understood as events that occur in the patient's life that lead to stress, such as financial losses, work difficulties, death of a close friend or family, or other family problems [3]. In our case, this information was provided by the patients themselves. Behavioural and pathophysiological changes have been reported as determining factors in these NLE on asthma. For the former aspect, self-care could be reduced, or inadequate use of the medication [32,37], and for the latter, an increase in airway inflammation has recently been demonstrated in asthmatic patients after stressful events [38].

Patients with more severe forms of asthma have a worse HRQoL, both in our population and in others $[8,39]$. However, a recent population study in the USA did not see a relationship between severity and the HRQoL [5]. Another study in a Japanese population,
Table 2 Factors associated with health-related quality of life, according dimensions of EuroQol-5D questionnaire ( $n=2,125)$

\begin{tabular}{lcc}
\hline A & $\begin{array}{c}\text { \% patients } \\
\text { without problems }\end{array}$ & $\begin{array}{c}\text { Mobility } \\
\text { Adjusted } \\
\text { OR (95\%Cl)* }\end{array}$ \\
\hline $\begin{array}{l}\text { Gender } \\
\text { Female }\end{array}$ & 1 \\
Male & $883 / 1,227(72.0 \%)$ & $1.49(1.13,1.97)$ \\
Age & $726 / 898(80.8 \%)$ & \\
$\geq 60$ years & $335 / 638(52.5 \%)$ & 1 \\
40 to 59 years & $551 / 704(78.3 \%)$ & $1.96(1.41,2.73)$ \\
18 to 39 years & $723 / 783(92.3 \%)$ & $4.13(2.71,6.32)$ \\
BMI (Kg/m $\left.{ }^{2}\right)$ & & 1 \\
$\geq 30$ & $243 / 424(57.3 \%)$ & $1.64(1.20,2.23)$ \\
$\geq 25$ to 30 & $656 / 873(75.1 \%)$ & $2.14(1.50,3.04)$ \\
$<25$ & $709 / 826(85.8 \%)$ & 1 \\
Educational level & & $1.46(0.97,2.20)$ \\
None & $74 / 170(43.5 \%)$ & $1.77(1.10,2.85)$ \\
Primary & $613 / 900(68.1 \%)$ & $3.19(1.73,5.88)$ \\
Secondary & $600 / 706(85.0 \%)$ & \\
University & $319 / 345(92.5 \%)$ &
\end{tabular}

\section{Occupation}

Non active worker

648/1,029 (63.0\%)

1

Active worker

960/1,094 (87.7\%)

$1.43(1.04,1.97)$

Living status

Lives alone

145/237 (61.2\%)

1

Lives with someone

1,461/1,885 (77.5\%)

$1.60(1.10,2.33)$

\section{ACQ score}

$>1.50$

$0.75-1.50$

$<0.75$

437/792 (55.2\%)

464/561 (82.7\%)

$2.68(1.96,3.66)$

708/772 (91.7\%)

$4.83(3.37,6.92)$

\section{Hospital admissions}

Yes

No

B

54/179 (30.2\%)

1,555/1,946 (79.9\%)

$2.64(1.71,4.07)$

$\%$ patients without problems

Self-care Adjusted OR $(95 \% \mathrm{Cl})^{*}$

\section{Age}

$\geq 60$ years

$335 / 638$ (52.5\%)

40 to 59 years

551/704 (78.3\%)

$2.25(1.34,3.75)$

18 to 39 years

723/783 (92.3\%)

$4.30(1.93,9.54)$

\section{Educational level}

None

$74 / 170$ (43.5\%)

1

Primary

613/900 (68.1\%)

$3.08(1.89,5.03)$

Secondary

600/706 (85.0\%)

$2.71(1.40,5.24)$

University

$319 / 345$ (92.5\%) 
Table 2 Factors associated with health-related quality of life, according dimensions of EuroQol-5D questionnaire ( $\mathbf{n}=\mathbf{2}, \mathbf{1 2 5})$ (Continued)

\begin{tabular}{l} 
Occupation \\
Non active worker \\
Active worker \\
Living status \\
Lives alone \\
Lives with someone \\
Asthma severity \\
Severe persistent \\
Moderate persistent \\
Mild persistent \\
Intermittent \\
Stressful event last 15 day \\
Yes \\
No \\
Asthma treatment \\
Oral corticosteroids \\
LABA + IC \\
Inhaled corticosteroids \\
SABA or LABA \\
ACQ score \\
$>1.50$ \\
$0.75-1.50$ \\
$<0.75$ \\
Hospital admissions \\
Yes \\
No \\
C \\
\hline
\end{tabular}

$648 / 1,029(63.0 \%)$

$960 / 1,094(87.7 \%)$

$145 / 237(61.2 \%)$

$1,461 / 1,885(77.5 \%)$

$28 / 90(31.1 \%)$

$449 / 706(63.6 \%)$

$655 / 774(84.6 \%)$

$476 / 554(85.9 \%)$

207/307 (67.4\%)

$1,394 / 1,810(77.0 \%)$

$62 / 158(39.2 \%)$

$1,114 / 1,476(75.5 \%)$

$180 / 209$ (86.1\%)

$230 / 255(90.2 \%)$

437/792 (55.2\%)

$464 / 561(82.7 \%)$

708/772 (91.7\%)

$54 / 179(30.2 \%)$

1,555/1,946 (79.9\%)

$\%$ patients

without problems

\section{Age}

$\geq 60$ years

40 to 59 years

18 to 39 years

BMI $\left(\mathrm{Kg} / \mathrm{m}^{2}\right)$

$$
\begin{aligned}
& \geq 30 \\
& \geq 25 \text { to } 30 \\
& <25
\end{aligned}
$$

Educational level

None

Primary

Secondary

University
335/638 (52.5\%)

$551 / 704$ (78.3\%)

723/783 (92.3\%)

243/424 (57.3\%)

656/873 (75.1\%)

709/826 (85.8\%)

74/170 (43.5\%)

613/900 (68.1\%)

600/706 (85.0\%)

$319 / 345$ (92.5\%)
$2.77(1.52,5.04)$

1

$1.70(1.03,2.80)$

1

$1.81(0.98,3.34)$

$3.32(1.61,6.85)$

$3.21(1.38,7.46)$

1

$1.99(1.22,3.26)$$$
1
$$$$
1.34(0.77,2.32)
$$$$
4.07(1.07,15.48)
$$$$
1.76(0.58,5.33)
$$$$
1
$$

$2.49(1.43,4.36)$

$2.69(1.41,5.14)$

$$
1
$$

$2.52(1.52,4.17)$

Usual activities Adjusted OR $(95 \% \mathrm{Cl})^{*}$

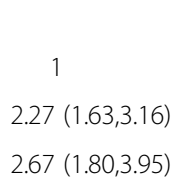

1
$1.27(0.93,1.73)$
$1.43(1.02,2.02)$

1
$1.51(0.99,2.31)$
$1.86(1.16,2.99)$
$2.62(1.49,4.60)$

Table 2 Factors associated with health-related quality of life, according dimensions of EuroQol-5D questionnaire ( $\mathbf{n}=\mathbf{2 , 1 2 5 )}$ (Continued)

Living status

Lives alone

145/237 (61.2\%)

Lives with someone

$1,461 / 1,885$ (77.5\%)

$1.76(1.23,2.53)$

Asthma severity

Severe persistent

Moderate persistent

28/90 (31.1\%)

1

449/706 (63.6\%)

$1.75(0.95,3.24)$

Mild persistent

655/774 (84.6\%)

$1.97(1.04,3.74)$

Intermittent

476/554 (85.9\%)

$1.76(0.90,3.45)$

Asthma treatment

Oral corticosteroids

62/158 (39.2\%)

$L A B A+I C$

$1,114 / 1,476$ (75.5\%)

$1.41(0.88,2.23)$

Inhaled corticosteroids

180/209 (86.1\%)

$2.43(1.27,4.62)$

SABA or LABA

230/255 (90.2\%)

$1.97(1.05,3.71)$

\section{ACQ score}

$>1.50$

$0.75-1.50$

$<0.75$

437/792 (55.2\%)

464/561 (82.7\%)

$3.74(2.79,5.09)$

708/772 (91.7\%)

$7.48(5.29,10.58)$

Hospital admissions

Yes

No

$54 / 179$ (30.2\%)

1,555/1,946 (79.9\%)

$1.75(1.14,2.68)$

Emergency visits

Yes

No

503/810 (62.1\%)

1,106/1,315 (84.1\%)

$1.67(1.28,2.17)$

D

$\%$ patients

without problems

Pain/Discomfort

Adjusted OR $(95 \% \mathrm{Cl})^{*}$

\section{Gender}

Female

Male

883/1,227 (72.0\%)

726/898 (80.8\%)

$1.55(1.17,2.06)$

\section{Age}

$\geq 60$ years

$335 / 638$ (52.5\%)

1

40 to 59 years

$551 / 704$ (78.3\%)

$2.32(1.68,3.22)$

18 to 39 years

723/783 (92.3\%)

$5.27(3.52,7.88)$

\section{BMI $\left(\mathrm{Kg} / \mathrm{m}^{2}\right)$}

$\geq 30$

$243 / 424$ (57.3\%)

1

$\geq 25$ to 30

656/873 (75.1\%)

$1.36(1.00,1.85)$

$<25$

$1.75(1.25,2.47)$

\section{Educational level}

None

709/826 (85.8\%)

74/170 (43.5\%)

$1.59(1.02,2.49)$

Primary

Secondary

University
$613 / 900(68.1 \%)$

600/706 (85.0\%)

$319 / 345$ (92.5\%)
$1.88(1.14,3.09)$

$2.23(1.25,3.99)$ 
Table 2 Factors associated with health-related quality of life, according dimensions of EuroQol-5D questionnaire ( $\mathbf{n}=\mathbf{2 , 1 2 5 )}$ (Continued)

\begin{tabular}{|c|c|c|}
\hline \multicolumn{3}{|l|}{ Occupation } \\
\hline Non active worker & 648/1029 (63.0\%) & 1 \\
\hline Active worker & 960/1094 (87.7\%) & $1.43(1.06,1.93)$ \\
\hline \multicolumn{3}{|l|}{ Asthma severity } \\
\hline Severe persistent & 28/90 (31.1\%) & 1 \\
\hline Moderate persistent & 449/706 (63.6\%) & $2.24(1.14,4.41)$ \\
\hline Mild persistent & 655/774 (84.6\%) & $3.35(1.66,6.75)$ \\
\hline Intermittent & 476/554 (85.9\%) & $2.65(1.28,5.48)$ \\
\hline \multicolumn{3}{|c|}{ Stressful event last 15 days } \\
\hline Yes & 207/307 (67.4\%) & 1 \\
\hline No & $1,394 / 1,810(77.0 \%)$ & $2.04(1.46,2.83)$ \\
\hline \multicolumn{3}{|l|}{ ACQ score } \\
\hline$>1.50$ & 437/792 (55.2\%) & 1 \\
\hline $0.75-1.50$ & 464/561 (82.7\%) & $1.80(1.33,2.44)$ \\
\hline$<0.75$ & 708/772 (91.7\%) & $2.78(1.99,3.88)$ \\
\hline \multicolumn{3}{|l|}{ Hospital admissions } \\
\hline Yes & $54 / 179(30.2 \%)$ & 1 \\
\hline No & $1,555 / 1,946(79.9 \%)$ & $2.05(1.30,3.25)$ \\
\hline \multicolumn{3}{|l|}{ Emergency visits } \\
\hline Yes & $503 / 810(62.1 \%)$ & 1 \\
\hline No & $1,106 / 1,315$ (84.1\%) & $1.37(1.03,1.81)$ \\
\hline E & $\begin{array}{c}\% \text { patients } \\
\text { without problems }\end{array}$ & $\begin{array}{c}\text { Anxiety/ } \\
\text { Depression } \\
\text { Adjusted } \\
\text { OR }(95 \% \mathrm{Cl})^{*}\end{array}$ \\
\hline
\end{tabular}

\section{Gender}

Female

Male

$883 / 1,227(72.0 \%)$

$726 / 898(80.8 \%)$

$335 / 638(52.5 \%)$

$551 / 704(78.3 \%)$

$723 / 783(92.3 \%)$

18 to 39 years

Educational level

None

Primary

Secondary

University

Place of residence

Rural

632/859 (73.6\%)

Urban

977/1265 (77.2\%)

Asthma severity

Severe persistent

Moderate persistent

28/90 (31.1\%)

449/706 (63.6\%)

Mild persistent

655/774 (84.6\%)

476/554 (85.9\%)
Table 2 Factors associated with health-related quality of life, according dimensions of EuroQol-5D questionnaire ( $\mathbf{n}=\mathbf{2 , 1 2 5 )}$ (Continued)

Stressful event last 15 days

Yes

207/307 (67.4\%)

$1,394 / 1,810$ (77.0\%)

$5.57(4.08,7.59)$

ACQ score

$>1.50$

0.75-1.50

437/792 (55.2\%)

1

$<0.75$

464/561 (82.7\%)

$1.36(1.01,1.83)$

Hospital admissions

Yes

708/772 (91.7\%)

$1.66(1.21,2.28)$

Yes

$54 / 179$ (30.2\%)

1

No

1,555/1,946 (79.9\%)

$2.09(1.36,3.22)$

Emergency visits

Yes

503/810 (62.1\%)

1

No 1,106/1,315 (84.1\%)

$1.32(1.02,1.72)$

${ }^{*}$ Adjusted Odds Ratio (Adjusted by all the variables in the Table 1 ).

NS, Crude Odds Ratio non significant; BMI, Body mass index; SABA, Shortacting beta2 agonists; LABA, Long-acting beta2 agonists; SD, Standard Deviation; IC, Inhaled corticosteroids.

observed deterioration in the HRQoL with the increasing severity of asthma in males, but not in females, establishing the possibility of different "coping styles" between the sexes [40].

Patients who remain in active employment have a better QoL, a similar finding to that of Siroux in a multicentre European study [8]. Lack of occupational activity is associated with a lower socio-economic income and greater psychological distress, which could be determining factors in the deterioration of the QoL $[3,41]$.

Living in an urban setting is associated with a better HRQoL. The same relationship was observed in a large study with Spanish children, suggesting the possibility that urban areas could have better access to the health system [42]. Other differences have also been identified in the management of the disease, with a lower likelihood of scheduled follow up or a greater underdiagnosis in patients in rural areas $[43,44]$.

The damaging effect of living alone appears to be confirmed, given that it is associated to a worse QoL. This is in agreement with other studies, where to live alone was a predictive factor of more visits to the Emergency Department, worse mental health or longer delay in the diagnosis $[29,45,46]$.

In other aspects analyzed, our findings agree with those mentioned in the literature, showing more exacerbations $[8,30]$; female sex $[8,47]$; less adherence to treatment [48]; being someone who never smoked [5,49]; and obesity $[8,50]$ are determining factors of a worse quality of life.

Our study may have some limitations. Firstly, being a cross-sectional study causality relationships cannot be 
Table 3 Factors associated with health-related quality of life: VAS scale $(0=$ worst health state, $100=$ best health state); ( $\mathrm{n}=\mathbf{2 0 3 4 )}$

\begin{tabular}{|c|c|c|c|}
\hline & \multirow[b]{2}{*}{$\mathbf{N}$} & \multicolumn{2}{|r|}{ VAS score } \\
\hline & & Mean (SD) & Adjusted mean differences ( $\mathrm{Cl} 95 \%)^{*}$ \\
\hline \multicolumn{4}{|l|}{$\overline{\text { Age }}$} \\
\hline$\geq 60$ years & 609 & $62.38(17.46)$ & \\
\hline 40 to 59 years & 675 & $68.93(16.66)$ & $1.78(-0.38,3.94)$ \\
\hline 18 to 39 years & 750 & $76.34(15.33)$ & $4.99(2.63,7.37)$ \\
\hline \multicolumn{4}{|l|}{ Educational level } \\
\hline None & 162 & $58.57(18.52)$ & \\
\hline Primary & 865 & $66.12(17.18)$ & $2.41(-0.63,5.44)$ \\
\hline Secondary & 667 & $73.48(16.02)$ & $4.96(1.64,8.28)$ \\
\hline University & 336 & $76.87(14.92)$ & $6.30(2.69,9.90)$ \\
\hline \multicolumn{4}{|l|}{ Asthma severity } \\
\hline Severe persistent & 87 & $46.78(17.21)$ & \\
\hline Moderate persistent & 672 & $65.45(16.86)$ & $9.01(5.07,12.96)$ \\
\hline Mild persistent & 754 & $72.97(15.12)$ & $11.40(7.28,15.52)$ \\
\hline Intermittent & 520 & $74.26(16.96)$ & $9.49(5.22,13.76)$ \\
\hline \multicolumn{4}{|l|}{ Smoking habit } \\
\hline Current or former & 753 & $68.47(17.02)$ & \\
\hline Never & 1,279 & $70.43(17.58)$ & $2.51(1.13,3.89)$ \\
\hline \multicolumn{4}{|c|}{ Stressful event last 15 days } \\
\hline Yes & 296 & $61.47(18.61)$ & \\
\hline No & 1,731 & $71.10(16.75)$ & $6.17(4.31,8.03)$ \\
\hline \multicolumn{4}{|c|}{ Adherence is important (score, patient's point of view): } \\
\hline$<8$ & 511 & $65.25(17.78)$ & \\
\hline$\geq 8$ & 1,521 & $71.23(16.98)$ & $4.02(2.54,5.50)$ \\
\hline \multicolumn{4}{|l|}{ ACQ score } \\
\hline$>1.50$ & 762 & $58.94(16.38)$ & \\
\hline $0.75-1.50$ & 541 & $72.59(13.89)$ & $9.48(7.53,11.44)$ \\
\hline$<0.75$ & 731 & 78.79 (14.48) & $13.26(11.22,15.29)$ \\
\hline
\end{tabular}

Score of VAS scale, and probability of obtaining values greater than the mean on the VAS. Multivariate analysis.

*Adjusted by all the variables in the Table 1.

$\mathrm{N}$, number of cases; VAS, Visual Analogue Scale; Cl, Confidence interval; BMI, Body mass index; SABA, Short-acting beta2 agonists; LABA, Long-acting beta2 agonists; IC, Inhaled corticosteroids.

defined. Secondly, the reference NLE is by self-report, as such any influence of the personality of the patients cannot be excluded. Thirdly, the selection of the participating doctors was not strictly randomized. However, given the high number of participating doctors and the distribution over the whole country, as well as the collection of data with validated tools like the EQ-5D questionnaire, the inclusion of a significant number of covariables that could have an influence on the quality of life, and the high number of patients analyzed, these results should be reasonably valid as representative of the reality of the QoL of asthmatics in Spain and its determining factors.

\section{Conclusions}

In our study, we could identify some factors related to worst quality of life in asthma patients.

The most significant were advanced age, lower education level, greater baseline severity of the asthma, presence of stressful events, poor control of the asthma, and need to be admitted to hospital.

We believe that the identification of factors related to poor asthma control, and particularly those that could be changed by the health care system [10], could lead to an improvement in the situation of asthmatic patients. Thus, the prevention and treatment of obesity and smoking, as well as reinforcing health education, seem 
to be basic aspects that could be performed by the health care system.

\section{Abbreviations}

HRQoL: Health-related quality of life; EQ-5D: EuroQol-5D; VAS: Visual analogue scale; BMI: Body mass index; GINA: Global Initiative for Asthma guide.

\section{Competing interests}

Mónica Tafalla and Javier Nuevo are employees of AstraZeneca Spain. The study was funded by AstraZeneca Spain.

\section{Authors' contributions}

Designed research/study: Mónica Tafalla, Javier Nuevo, Francisco CaamañoIsorna. Performed research/study: Mónica Tafalla, Javier Nuevo, Francisco Caamaño-Isorna. Collected data: Mónica Tafalla, Javier Nuevo, Francisco Caamaño-Isorna. Analyzed data: Francisco-Javier Gonzalez-Barcala, Ramon de la Fuente-Cid, MónicaTafalla, Javier Nuevo, Francisco Caamaño-Isorna. Wrote paper: Francisco-Javier Gonzalez-Barcala, Ramon de la Fuente-Cid. All authors read and approved the final manuscript.

\section{Author details}

'Pneumology Department, Clinic University Hospital, C/Choupana SN 15706, Santiago de Compostela, Spain. ${ }^{2}$ Internal Medicine Department, Clinic University Hospital, Santiago de Compostela, Spain. ${ }^{3}$ Medical Department, AstraZeneca Farmacéutica, Madrid, Spain. ${ }^{4} \mathrm{C}$ IBER of Epidemiology and Public Health (CIBERESP), Preventive Medicine Department, University of Santiago de Compostela, Santiago de Compostela, Spain.

Received: 2 May 2012 Accepted: 25 July 2012

Published: 2 October 2012

\section{References}

1. Braido F, Bousquet PJ, Brzoza Z, et al: Specific recommendations for PROs and HRQoL assessment in allergic rhinitis and/or asthma: a GA(2)LEN taskforce position paper. Allergy 2010, 65(8):959-968.

2. Baiardini I, Braido F, Brandi S, Tarantini F, Bonini S, Bousquet PJ, Zuberbier T, Demoly P, Canonica GW: The impact of GINA suggested drugs for the treatment of asthma on Health-Related Quality of Life: a GA(2)LEN review. Allergy 2008, 63(8):1015-1030.

3. Archea $\mathrm{C}$, Yen $\mathrm{HH}_{\text {, }}$ Chen $\mathrm{H}$, Eisner MD, Katz PP, Masharani U, Yelin EH, Earnest G, Blanc PD: Negative life events and quality of life in adults with asthma. Thorax 2007, 62(2):139-146.

4. Bateman ED, Bousquet J, Keech ML, Busse WW, Clark TJ, Pedersen SE: The correlation between asthma control and health status: the GOAL study. Eur Respir J 2007, 29(1):56-62.

5. Chen H, Gould MK, Blanc PD, Miller DP, Kamath TV, Lee JH, Sullivan SD, for the TENOR Study Group: Asthma control, severity, and quality of life: quantifying the effect of uncontrolled disease. J Allergy Clin Immunol 2007, 120(2):396-402.

6. Juniper EF, Wisniewski ME, Cox FM, Emmett AH, Nielsen KE, O'Byrne PM: Relationship between quality of life and clinical status in asthma: a factor analysis. Eur Respir J 2004, 23(2):287-291.

7. Pickard AS, Wilke C, Jung E, Patel S, Stavem K, Lee TA: Use of a preferencebased measure of health (EQ-5D) in COPD and asthma. Respir Med 2008, 102(4):519-536.

8. Siroux V, Boudier A, Anto JM, et al: Quality-of-life and asthma-severity in general population asthmatics: results of the ECRHS II study. Allergy 2008, 63(5):547-554

9. Ford ES, Mannino DM, Redd SC, Moriarty DG, Mokdad AH: Determinants of quality of life among people with asthma: findings from the Behavioral Risk Factor Surveillance System. J Asthma 2004, 41(3):327-336.

10. González Barcala FJ, de la Fuente-Cid R, Alvarez-Gil R, Tafalla M, Nuevo J, Caamaño-Isorna F: Factors associated with asthma control in primary care patients: the CHAS study. Arch Bronconeumol 2010, 46(7):358-363.

11. Global strategy for asthma management and prevention (updated 2006). Retrieved 15 July, 2010, from http://www.ginasthma.org.

12. MCTaggart-Cowan HM, Marra CA, Yang Y, Brazier JE, Kopec JA, FitzGerald $J M$, Anis AH, Lynd LD: The validity of generic and condition-specific preference-based instruments: the ability to discriminate asthma control status. Qual Life Res 2008, 17(3):453-462.
13. Juniper EF, Bousquet J, Abetz L, Bateman ED: GOAL Committee. Identifying 'well-controlled' and 'not well-controlled' asthma using the Asthma Control Questionnaire. Respir Med 2006, 100(4):616-621.

14. Reddel HK, Taylor DR, Bateman ED, et al: An official American Thoracic Society/European Respiratory Society statement: asthma control and exacerbations: standardizing endpoints for clinical asthma trials and clinical practice. Am J Respir Crit Care Med 2009, 180(1):59-99.

15. Garratt AM, Hutchinson A, Russell I: Patient-assessed measures of health outcome in asthma: a comparison of four approaches. Respir Med 2000, 94(6):597-606.

16. Hazell M, Frank T, Frank P: Health related quality of life in individuals with asthma related symptoms. Respir Med 2003, 97(11):1211-1218.

17. Szende A, Svensson K, Ståhl E, Mészáros A, Berta GY: Psychometric and utility-based measures of health status of asthmatic patients with different disease control level. Pharmacoeconomics 2004, 22(8):537-547.

18. Ferrer A, Formiga F, Almeda J, Alonso J, Brotons C, Pujol R: Calidad de vida en nonagenarios: género, funcionalidad y riesgonutricionalcomofactoresasociados. Med Clin (Barc) 2010, 134(7):303-306.

19. Badia X, Roset M, Montserrat S, Herdman M, Segura A: La versiónespañoladelEuroQol: descripción y aplicaciones. Med Clin 1999, 112(Supl 1):79-86.

20. Apter AJ, Reisine ST, Affleck G, Barrows E, ZuWallack RL: The influence of demographic and socioeconomic factors on health-related quality of life in asthma. J Allergy Clin Immunol 1999, 103(1 Pt 1):72-78.

21. Erickson SR, Christian RD Jr, Kirking DM, Halman LJ: Relationship between patient and disease characteristics, and health-related quality of life in adults with asthma. Respir Med 2002, 96(6):450-460.

22. Plaza V, Serra-Batlles J, Ferrer M, Morejón E: Quality of life and economic features in elderly asthmatics. Respiration 2000, 67(1):65-70.

23. Gibson PG, McDonald VM, Marks GB: Asthma in older adults. Lancet 2010, 376:803-813.

24. Bellia V, Scichilone N, Battaglia S: Asthma in the elderly. Eur Respir Mon 2009, 43:56-76.

25. Busse PJ, Mathur SK: Age-related changes in immune function: effect on airway inflammation. J Allergy Clin Immunol 2010, 126:690-699.

26. Mancuso CA, Rincon M: Impact of health literacy on longitudinal asthma outcomes. J Gen Intern Med 2006, 21(8):813-817.

27. Apter AJ, Wang X, Bogen D, Bennett IM, Jennings RM, Garcia L, Sharpe T, Frazier C, Ten Have T: Linking numeracy and asthma-related quality of life. Patient Educ Couns 2009, 75(3):386-391.

28. Mangan JM, Wittich AR, Gerald LB: The potential for reducing asthma disparities through improved family and social function and modified health behaviors. Chest 2007, 132(5 Suppl):789S-801S.

29. Santos MS, Jung H, Peyrovi J, Lou W, Liss GM, Tarlo SM: Occupational asthma and work-exacerbated asthma: factors associated with time to diagnostic steps. Chest 2007, 131(6):1768-1775.

30. Schatz M, Zeiger RS, Mosen D, Vollmer WM: Asthma-specific quality of life and subsequent asthma emergency hospital care. Am J Manag Care 2008, 14:206-211.

31. Braido F, Baiardini I, Balestracci S, Ghiglione V, Stagi E, Ridolo E, Nathan R, Canonica GW: Does asthma control correlate with quality of life related to upper and lower airways? A real life study. Allergy 2009, 64(6):937-943.

32. Schmitz N, Wang J, Malla A, Lesage A: The impact of psychological distress on functional disability in asthma: results from the Canadian community health survey. Psychosomatics 2009, 50(1):42-49.

33. Wang G, Zhou T, Wang L, Wang L, Fu JJ, Zhang HP, Ji YL: Relationship between current psychological symptoms and future risk of asthma outcomes: a 12-month prospective cohort study. J Asthma 2011 Dec, 48(10):1041-1050.

34. Avallone KM, McLeish AC, Luberto CM, Bernstein JA: Anxiety sensitivity, asthma control, and quality of life in adults with asthma. J Asthma 2012 Feb, 49(1):57-62.

35. Lavoie KL, Bacon SL, Barone S, Cartier A, Ditto B, Labrecque M: What is worse for asthma control and quality of life: depressive disorders, anxiety disorders, or both? Chest 2006, 130(4):1039-1047.

36. Heaney LG, Conway E, Kelly C, Gamble J: Prevalence of psychiatric morbidity in a difficult asthma population: relationship to asthma outcome. Respir Med 2005, 99(9):1152-1159.

37. Wright RJ: Further evidence that the wealthier are healthier: negative life events and asthma-specific quality of life. Thorax 2007, 62:106-108. 
38. Ritz T, Ayala ES, Trueba AF, Vance CD, Auchus RJ: Acute Stress-induced Increases in Exhaled Nitric Oxide in Asthma and their Association with Endogenous Cortisol. Am J Respir Crit Care Med. in press.

39. Lavoie KL, Bouthillier D, Bacon SL, Lemière C, Martin J, Hamid Q, Ludwig M, Olivenstein R, Ernst P: Psychologic distress and maladaptive coping styles in patients with severe vs moderate asthma. Chest 2010, 137(6):1324-1331.

40. Kimura T, Yokoyama A, Kohno N, Nakamura H, Eboshida A: Perceived stress, severity of asthma, and quality of life in young adults with asthma. Allergol Int 2009, 58(1):71-79.

41. Oraka E, King ME, Callahan DB: Asthma and serious psychological distress: prevalence and risk factors among US adults, 2001-2007. Chest 2010, 137(3):609-616.

42. García-Marcos L, CarvajalUrueña I, EscribanoMontaner A, FernándezBenítez M, García de la Rubia S, Tauler Toro E, Pérez Fernández V, Barcina Sánchez C: Seasons and other factors affecting the quality of life of asthmatic children. J Investig Allergol Clin Immunol 2007, 17(4):249-256.

43. Withy K, Davis J: Followup after an emergency department visit for asthma: urban/rural patterns. Ethn Dis 2008, 18(2 Suppl 2):S2-247-251.

44. Ownby DR: Asthma in rural America. Ann Allergy Asthma Immunol 2005, 95(5 Suppl 1):S17-S22.

45. Hanania NA, David-Wang A, Kesten S, Chapman KR: Factors associated with emergency department dependence of patients with asthma. Chest 1997, 111(2):290-295.

46. Chun TH, Weitzen SH, Fritz GK: The asthma/mental health nexus in a population-based sample of the United States. Chest 2008, 134(6):1176-1182.

47. Sundberg R, Palmqvist $M$, Tunsäter $A$, Torén $K$ : Health-related quality of life in young adults with asthma. Respir Med 2009, 103(10):1580-1585.

48. Gamble J, Stevenson M, McClean E, Heaney LG: The prevalence of nonadherence in difficult asthma. Am J Respir Crit Care Med 2009, 180(9):817-822.

49. Lazarus SC, Chinchilli VM, Rollings NJ, et al: Smoking affects response to inhaled corticosteroids or leukotriene receptor antagonists in asthma. Am J Respir Crit Care Med 2007, 175(8):783-790.

50. Sutherland ER, Lehman EB, Teodorescu M, Wechsler ME: National Heart, Lung, and Blood Institute's Asthma Clinical Research Network. Body mass index and phenotype in subjects with mild-to-moderate persistent asthma. J Allergy Clin Immunol 2009, 123(6):1328-1334.

doi:10.1186/2049-6958-7-32

Cite this article as: Gonzalez-Barcala et al:: Factors associated with health-related quality of life in adults with asthma. A cross-sectional study. Multidisciplinary Respiratory Medicine 2012 7:32.

\section{Submit your next manuscript to BioMed Central and take full advantage of:}

- Convenient online submission

- Thorough peer review

- No space constraints or color figure charges

- Immediate publication on acceptance

- Inclusion in PubMed, CAS, Scopus and Google Scholar

- Research which is freely available for redistribution

Submit your manuscript at www.biomedcentral.com/submit
Biomed Central 